\title{
Mamdani Fuzzy Expert System Based Directional Relaying Approach for Six-Phase Transmission Line
}

\author{
A. Naresh $\operatorname{Kumar}^{1 *}$, Ch. Sanjay², M. Chakravarthy ${ }^{3}$ \\ ${ }^{1}$ Department of Electrical and Electronics Engineering, Institute of Aeronautical Engineering, Hyderabad \\ (India) \\ ${ }^{2}$ Department of Mechanical Engineering, GITAM University, Hyderabad (India) \\ ${ }^{3}$ Department of Electrical and Electronics Engineering, Vasavi College Engineering, Hyderabad (India)
}

Received 14 December 2018 | Accepted 29 May 2019 | Published 21 June 2019

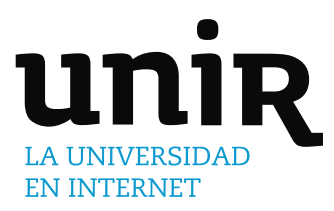

Traditional directional relaying methods for 6-phase transmission lines have complex effort, and so there is still a need for novel direction relaying estimation scheme. This study presents a Mamdani-fuzzy expert system (MFES) approach for discriminating faulty section/zone, classifying faults and locating faults in 6-phase transmission lines. The 6-phase fundamental component of currents, voltages and phase angles are captured at single bus and are used in the protection scheme. Simulation results substantiate that the protection scheme is very successful against many parameters such as different fault types, fault resistances, transmission line fault locations and inception angles. A large number of fault case studies have been carried out to evaluate reach setting and $\%$ error of proposed method. It provides primary protection to transmission line length and also offers backup protection for a reverse section of transmission line. The experimental results show that the scheme performs better than the other schemes.

Fault Protection, Fuzzy Systems, Simulation, Transmission Lines.

\section{INTRODUCTION}

$\mathrm{T}$ HE demand for electrical power is always increasing, as a rule of thumb, it doubles every decade. In order to reach this booming demand, power transfer capability of the transmission lines is required to be improved continuously. It can be done either by enhancing the voltage handling capability or by upgrading the existing power transmission systems to multi-phase (i.e. 6, 9 and 12-phase) transmission systems. The multi-phase transmission serves as an optimal solution to handle high power transfer capacity of existing transmission systems. Existing single and double circuit 3-phase transmission lines can easily be modified to operate as a single circuit 6-phase transmission line. Apart from improved power transfer capacity, 6-phase transmission systems provide several other benefits over traditional 3-phase double circuit transmission line viz. higher efficiency, lesser corona, higher thermal loading capability, better surge impedance, good voltage regulation, lesser audible noise levels, lesser radio interference and lesser conductor surface gradient. The 6-phase line theory and benefits are described in [1]-[2]. Existing $115 \mathrm{kV}$, double circuit 3-phase transmission line was modified into $93 \mathrm{kV}, 2.4 \mathrm{~km}, 6$ phase line configuration in between Goudey-Okadale substations. The $93 \mathrm{kV}$, configuration research was conducted for three years from 1992 to 1995 , after it was replaced to its original $115 \mathrm{kV}$, double circuit 3-phase transmission line configuration [3] because of the failure of 6-phase line protection. Although 6-phase line offers more benefits to electrical power system operations, the fault protection task in 6-phase

* Corresponding author.

E-mail address: ankamnaresh29@gmail.com line is more difficult than in double circuit 3-phase transmission lines. It can cause permanent damage to the transmission lines. Thus, early identification is needed to minimize the incidences severity of power system damages.

Till now, several techniques have been focusing on locating and classifying faults in 6-phase transmission line [4]-[8]. In [4], the fundamental component of measured currents is used for fault detection and classification. In [5], the Haar Wavelet Transform measured currents are employed for fault detection and classification. A methodology based on current measurements for locating faults is provided in [6]. Modular artificial neural network (ANN) scheme is demonstrated [7] for fault classification and location based on fundamental component voltages and currents. Same Modular ANN scheme is addressed [8] for fault classification and location based on wavelet transform voltages and currents. Nonetheless, all the aforementioned schemes are relevant to normal fault classification and location but they are not applicable for directional relaying. Only a few researchers have illustrated directional relaying in 6-phase transmission lines [9]-[10], but these methods do not classify and locate the faults. In [11], a neuro-wavelet algorithm for zone/section identification and fault location in 6-phase transmission lines is suggested. The directional relaying algorithms are developed using linear discriminant analysis [12], adaptive neuro-fuzzy inference system [13], decision tree [14] and ANN [15] methods. Among all the soft computing methods, fuzzy expert system (FES) is employed mostly in transmission line protection applications owing to less computation work and easy implementation, unlike other soft computing techniques. Some notable works have been reported in the literature on the soft computing techniques [16]-[18]. Fuzzy with single end directional relaying scheme for transmission line compensated by fixed series capacitor have been 
addressed in [19]. Some studies using FES for fault classification and location in transmission lines have been published [20]-[23]. Fuzzy based model with better performance of directional relaying on double circuit transmission lines has been introduced in [24]. However, none of the authors have given the solution to discriminate faults in 6-phase transmission lines without complex effort considering the fundamental currents and MFES scheme. Therefore, a novel zone identification scheme using fuzzy inference system is presented in this paper. This paper will further develop to deal with fault location and classification.

The structure of the paper is as follows. Section II describes the transmission line system. In Section III, a Mamdani fuzzy idea for fault direction, classification and location is described. The simulation results and discussions are explained in Section IV. Finally, in Section $\mathrm{V}$, conclusive remarks are given.

\section{TRANSMISSION LINE}

As depicted in Fig. 1, a single line diagram of 6-phase transmission line connecting between two substations namely Springdale and McCalmont is used to clarify the presented schemes. The network consists of a $138 \mathrm{kV}, 60 \mathrm{~Hz}$ transmission line of length $200 \mathrm{~km}$ divided into two zones of $100 \mathrm{~km}$ each. The relay is located at bus- 2 which gives protection to the total transmission line. The distributed line parameter blocks are employed to model 6-phase line system while fault breakers are used to simulate faults. The zone between the sending terminal and the relaying point is considered as reverse section (zone1 ) and the zone between the relaying point and the receiving terminal is the forward section (zone-2). The 6-phase line is simulated using Simulink ${ }^{\circledR}$ and Simpowersystem ${ }^{\circledR}$ toolboxes of MATLAB.

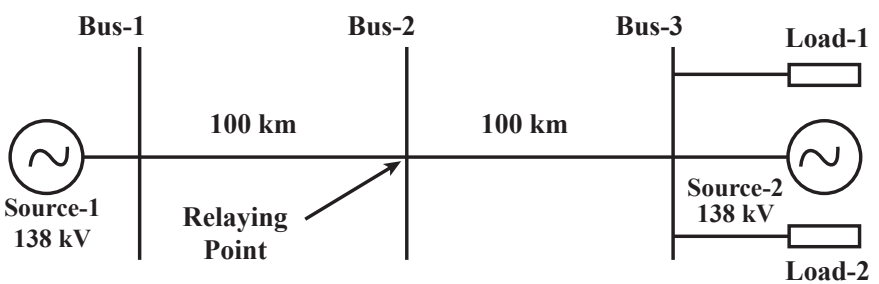

Fig. 1. Diagram of the studied system.

Fig. 2 represents the six phase voltages of D-g fault at $46 \mathrm{~ms}$ of time at $42 \mathrm{~km}$ for fault resistance of $10 \Omega$. Fig. 3 sketches the six phase currents of D-g fault at $46 \mathrm{~ms}$ of time at $42 \mathrm{~km}$ for fault resistance of $10 \Omega$. The zero sequence current during D-g fault is shown in Fig. 4. The phase angle of positive sequence current during D-g fault in the forward zone is seen in Fig. 5. The recorded instantaneous 6-phase currents and voltages are applied to a $2^{\text {nd }}$ order low pass Butterworth filter. The filter cut-off frequency is kept at $480 \mathrm{~Hz}$. After that, these currents and voltages are sampled with a frequency of $1.2 \mathrm{kHz}$. This frequency has been chosen based on the Nyquist sampling criteria. Then, these signals are fed to one full cycle discrete fourier transform for estimation of the fundamental components of 6-phase currents and voltages. Now, these currents and voltages are normalized in between -1 to +1 . From the fundamental component of currents and voltages, the fundamental component of impedances is obtained using equation (1). From the fundamental component of impedances, 35 post-fault cases are selected after the full cycle of fault occurrence. Mean impedance is computed using equation (2), which changes from position to position for various types of fault.

$\mathrm{Z}=\mathrm{Vf} / \mathrm{If}$

Where Z - fundamental component of impedance,

$\mathrm{Vf}$ - fundamental component of voltage and

If - fundamental component of current

$\mathrm{Zm}=\sum_{\mathrm{k}=1}^{\mathrm{n}} \mathrm{Zk} / \mathrm{n}$

Where $\mathrm{Zm}$ - Mean fundamental component of impedance and

$$
\mathrm{n} \text { - Number of fault samples chosen. }
$$

To analyze the currents and voltages of the line during faulty condition, consider a single phase to ground fault (D-g) has occurred at $46 \mathrm{~ms}$ time. Before the inception of fault, the 6-phase currents and voltages in all the phases are same and zero sequence component of current and phase angle has zero amplitude. At $46 \mathrm{~ms}$ D-phase current increases and voltage decreases while other phase currents remain same. As a result, the fault impedance increases. The fault current decreases, voltage increases and impedance increases as the fault location increases away from bus-2. The zero sequence component current starts to increase and phase angle starts to decrease in case of forward zone. The fuzzy schemes for the protection of a 6-phase line are based on these changes in currents, voltages, impedances and phase angles under pre-fault and post-fault conditions. The simple flowchart for the proposed scheme is depicted in Fig. 6. It consists of three stages, including faulty section detection, fault type classification and fault location.

\section{MFES SCHEMES MODELING}

Although the fuzzy theory was first introduced by Zadeh in 1960s, its application to the protection of transmission lines is somewhat recent. The FES is a popular computing scheme based on the concepts of

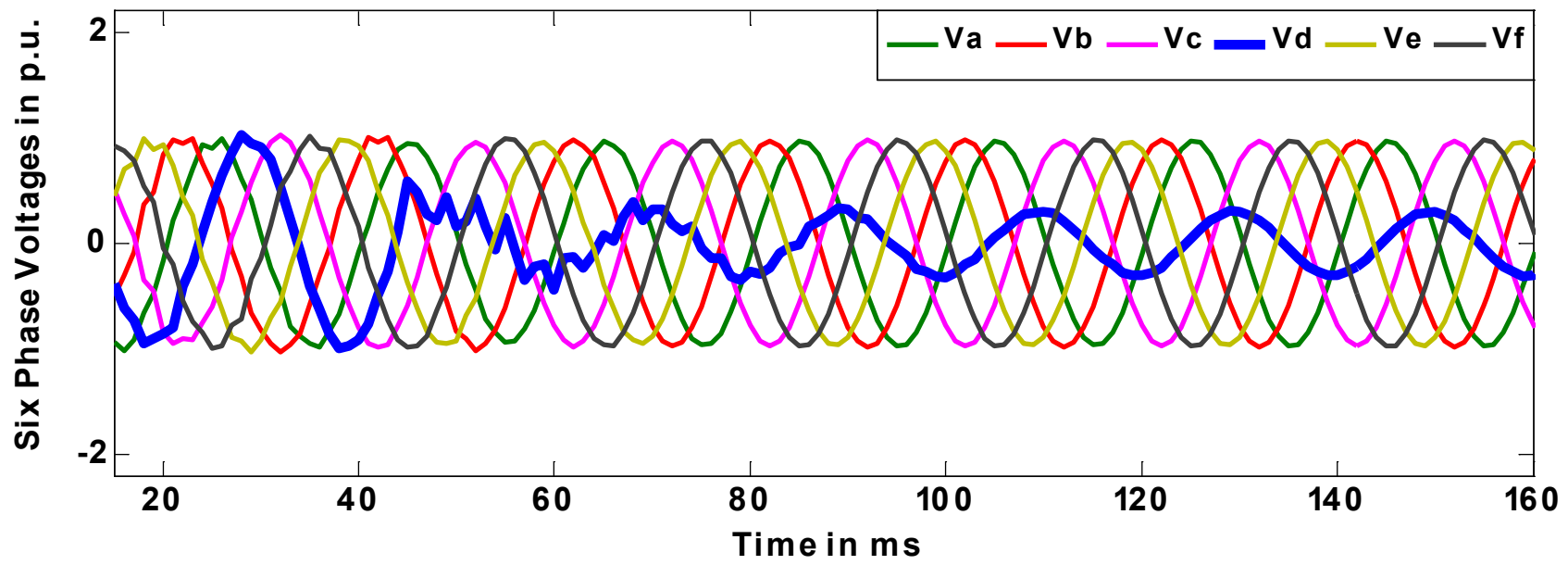

Fig. 2. Six-phase voltages during ' $D$-g' phase to ground fault. 


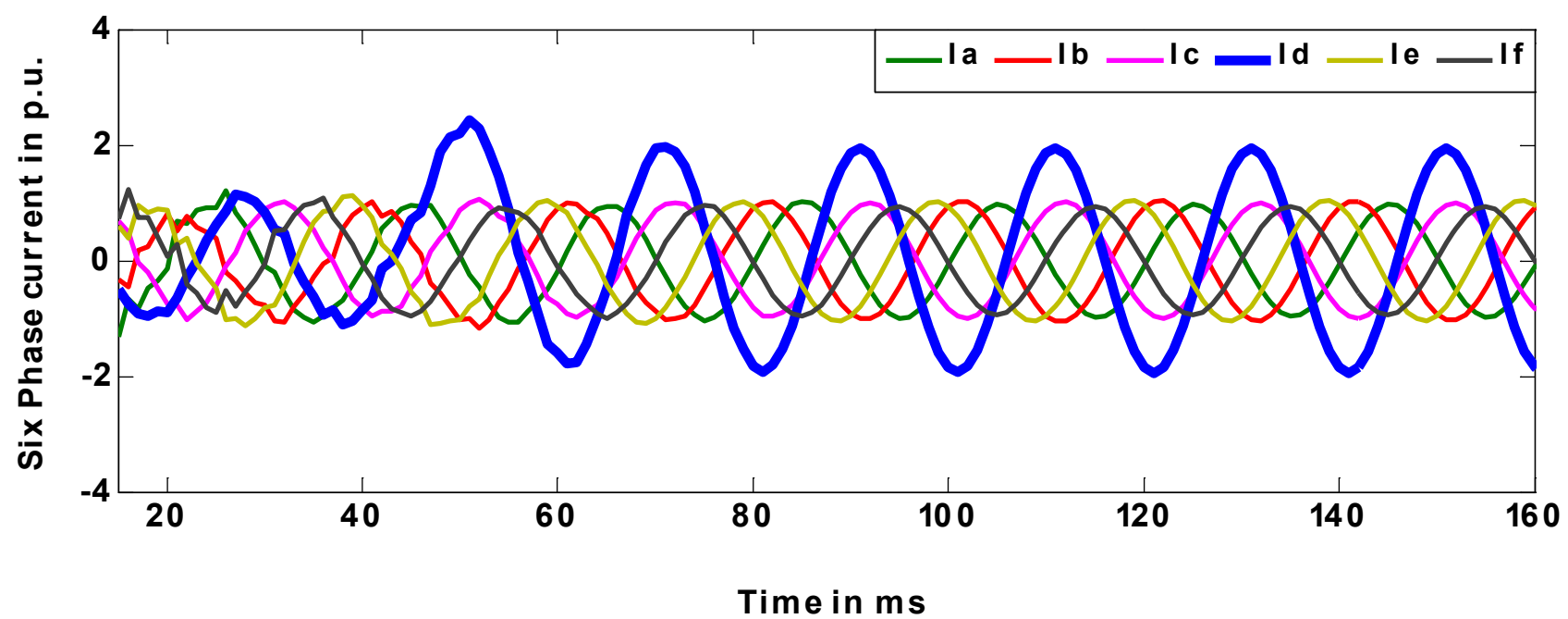

Fig. 3. Six-phase currents during 'D-g' phase to ground fault.

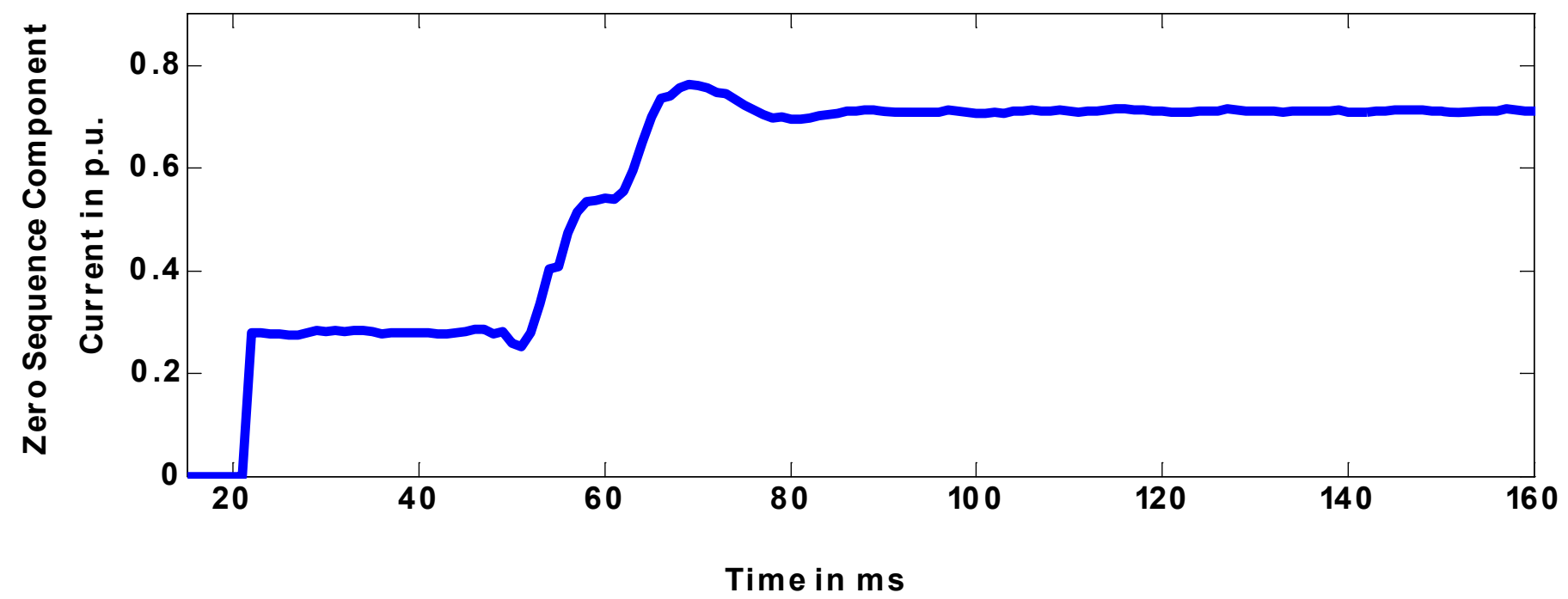

Fig. 4. Zero sequence current during 'D-g' phase to ground fault.

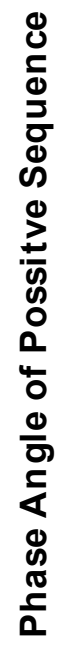

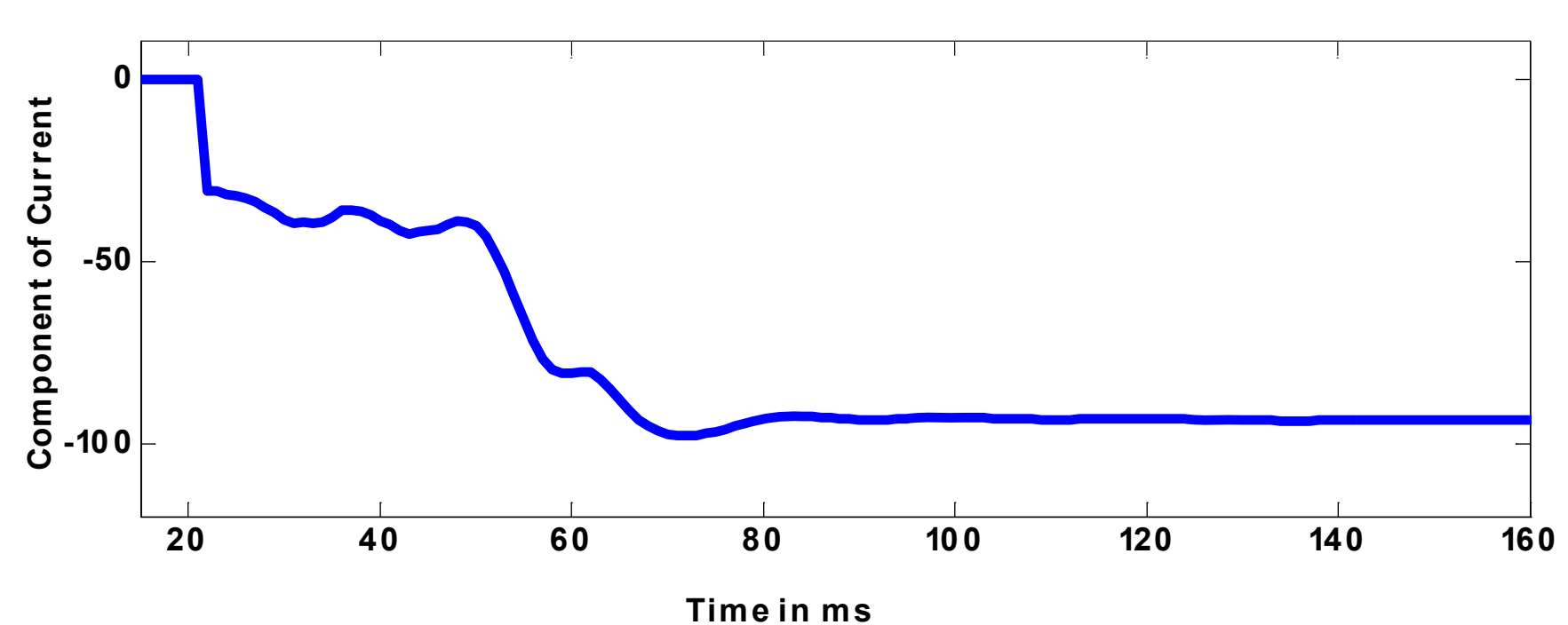

Fig. 5. Phase angle of positive sequence current during 'D-g' phase to ground fault. 
fuzzy set theory, reasoning and if-then rules. It has been successfully employed in a wide variety of field's viz. data classification, automatic control, decision analysis, pattern recognition and robotics. The process of formulating the nonlinear mapping from a given input to an output based on fuzzy logic is known as fuzzy inference. Fig. 7 shows a diagram of general FES. The basic structure of FES consists of four conceptual components: fuzzification, rule base, inference engine and defuzzification. The fuzzification unit maps a vector input of scalar values into corresponding fuzzy sets. The rule base consists of linguistic rules that are often defined by domain experts. When a rule has multiple antecedents, the fuzzy operation is employed to determine a single firing strength in inference engine. The aggregator combines the output fuzzy sets into a single fuzzy set. The defuzzification unit then transfers the output fuzzy sets into a crisp value, which is the final output of FES. There are two kinds of FES schemes that can be implemented in the Fuzzy Toolbox: Mamdani and Takagi-Sugeno. Mamdani fuzzy expert system is the most commonly seen inference system. Mamdani fuzzy inference was first introduced by Mamdani and Assilian in 1975. The steps involved in the MFES scheme are explained in Fig. 8. The building of fuzzy schemes are described the next step.

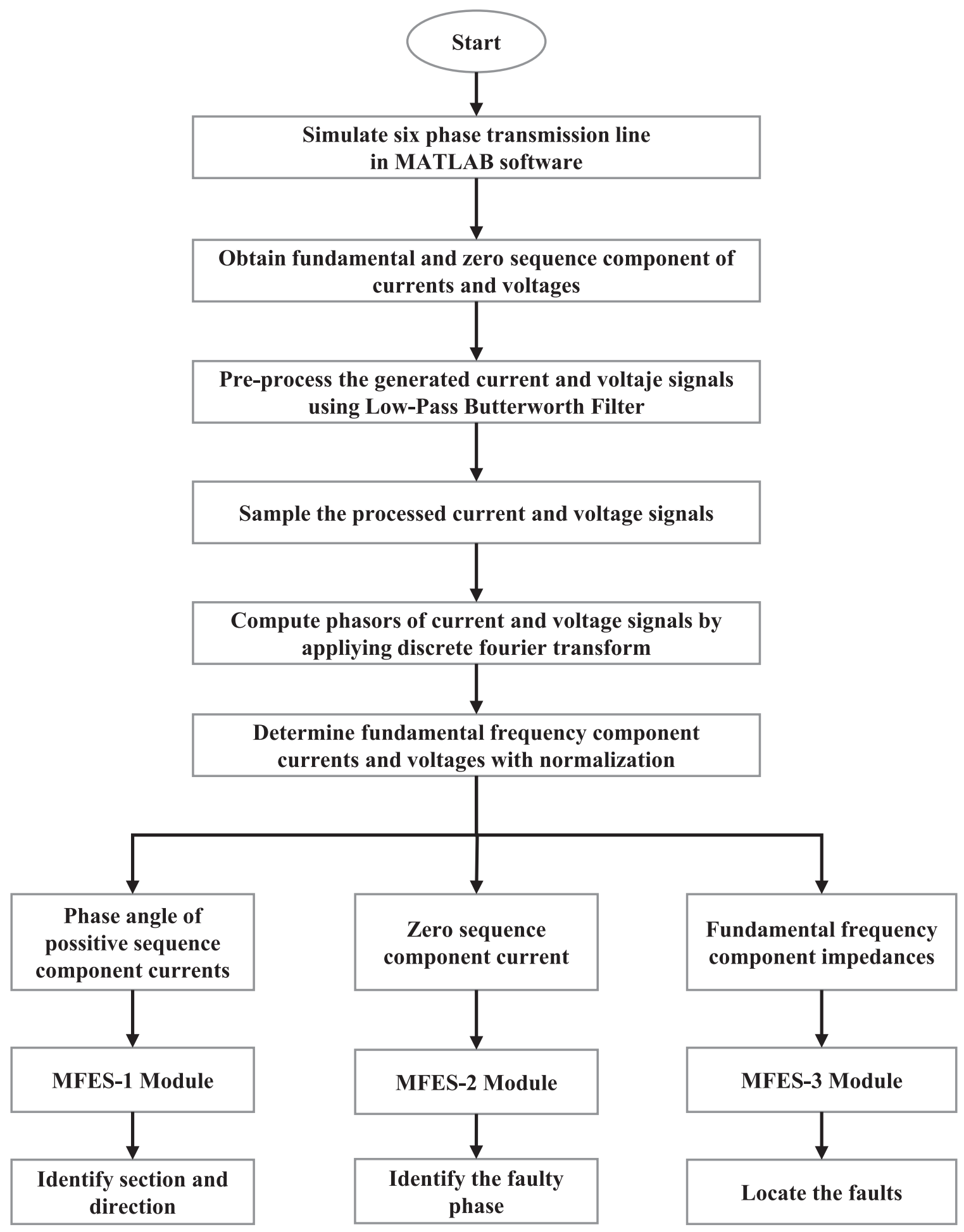

Fig. 6. Proposed protection scheme. 


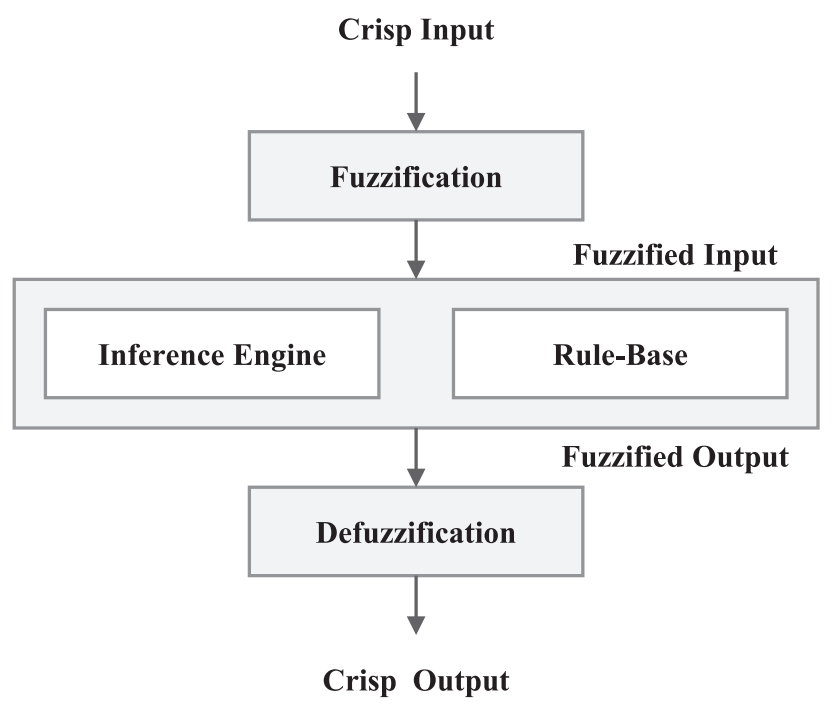

Fig. 7. Outline of FES.

\begin{tabular}{|c|c|}
\hline \multicolumn{2}{|r|}{ Approach: MFES } \\
\hline Stage 1: & Fuzzification \\
\hline Step 1: & Determining a set of fuzzy rules \\
\hline Step 2: & Fuzzifying the inputs using membership function \\
\hline Stage 2: & Rule Evaluation \\
\hline Step 1: & $\begin{array}{l}\text { Combining the fuzzified inputs according to the fuzzy rules to } \\
\text { establish rule strength. }\end{array}$ \\
\hline Step 2: & $\begin{array}{l}\text { Finding the consequence of the rule by combining the rule } \\
\text { strength and the output MF }\end{array}$ \\
\hline Step 3: & Combining the consequences to get an output distribution \\
\hline Stage 3: & Defuzzification \\
\hline Step 1: & Defuzzifying the output distribution \\
\hline
\end{tabular}

Fig. 8. Steps involved in the MFES scheme.

For the protection system three MFES schemes have been designed namely MFES-1, MFES-2 and MFES-3 to identify the faulty zone, classify and locate the faults, respectively. All the fuzzy schemes are modeled based on the Mamdani technique only. In the first scheme, MFES-1 is used by applying the phase angle of positive sequence current only to identify the faulty zone/section, whether the fault is on section-1 or on section-2. After that MFES-2 is developed by employing the fundamental component and zero sequence components of current to classify the faults. Further, MFES-3 is designed by using impedances in each phase to locate the fault. The first scheme (MFES-1) has one input parameter, 3 rules and one output. The second scheme (MFES-2) has seven input parameters, 120 rules and seven outputs whereas the third model (MFES-3) has also six input parameters, 8 rules and one output. The linguistic variable names, membership function (MF) names and MF type in each input-output for MFES-1, MFES-2 and MFES-3 are illustrated in Table-I. Fuzzy operators 'OR' and 'AND' have been recommended to connect input MFs. The minimum method is chosen to determine the firing strength.
The aggregation used here is the maximum method. Then the centroid method of defuzzification is employed. After completion of modeling, proposed MFES schemes can provide accurate results by interring/ giving the proper input parameters.

\section{IF-THEN rules for MFES-1}

R1: IF (Phase angle is Small) THEN (Zone is Forward Zone)

R2: IF (Phase angle is Normal) THEN (Zone is No-Fault)

R3: IF (Phase angle is Large) THEN (Zone is Reverse Zone)

\section{IF-THEN rules for MFES-2}

IF (Input MF is Low) THEN (Output MF is Healthy)

IF (Input MF is High) THEN (Output MF is Faulty)

\section{IF-THEN rules for MFES-3}

$\mathrm{R} 1$ : IF (FCZa is Z1) or (FCZb is Z1) or (FCZc is Z1) or (FCZd is $\mathrm{Z1}$ ) or (FCZe is Z1) or (FCZf is Z1) THEN (L is FL1)

R2: IF (FCZa is Z2) or (FCZb is Z2) or (FCZc is Z2) or (FCZd is $\mathrm{Z2}$ ) or (FCZe is Z2) or (FCZf is Z2) THEN (L is FL2)

R3: IF (FCZa is Z3) or (FCZb is Z3) or (FCZc is Z3) or (FCZd is $\mathrm{Z3}$ ) or (FCZe is Z3) or (FCZf is Z3) THEN (L is FL3)

$\mathrm{R} 4$ : IF (FCZa is Z4) or (FCZb is Z4) or (FCZc is Z4) or (FCZd is $\mathrm{Z4}$ ) or (FCZe is Z4) or (FCZf is Z4) THEN (L is FL4)

R5: IF (FCZa is Z5) or (FCZb is Z5) or (FCZc is Z5) or (FCZd is $\mathrm{Z5}$ ) or (FCZe is Z5) or (FCZf is Z5) THEN (L is FL5)

R6: IF (FCZa is Z6) or (FCZb is Z6) or (FCZc is Z6) or (FCZd is $\mathrm{Z6}$ ) or (FCZe is Z6) or (FCZf is Z6) THEN (L is FL6)

R7: IF (FCZa is Z7) or (FCZb is Z7) or (FCZc is Z7) or (FCZd is $\mathrm{Z7}$ ) or (FCZe is Z7) or (FCZf is Z7) THEN (L is FL7)

$\mathrm{R} 8$ : IF (FCZa is Z8) or (FCZb is Z8) or (FCZc is Z8) or ( FCZd is $\mathrm{Z8}$ ) or (FCZe is Z8) or (FCZf is Z8) THEN (L is FL8)

\section{A. MFES Modeling in MATLAB Software}

\section{Fuzzification}

The transformation from input numerical to fuzzy is called as fuzzification. Numerical inputs are changed to their fuzzy equivalent by a family of MFs. In MFES-1, input represents phase angle. The output represents Zone. The three types of triangular MFs viz. Small, Normal and Large are designed for input as illustrated in Fig. 9 and three types of triangular MFs viz. Reverse Zone, No-Fault and Forward Zone are designed for output as illustrated in Fig. 10. In MFES-2, inputs represent FCIa, FCIb, FCIc, FCId, FCIe, FCIf and ZSCC. The outputs represent A, B, C, D, E, F, G. The two types of trapezoidal MFs viz. Low and High are designed for each input as illustrated in Fig. 11 and two types of triangular MFs viz. Faulty and Healthy are designed for each output as illustrated in Fig. 12. In MFES-3, inputs represent FCZa, FCZb, FCZc, FCZd, FCZe, FCZf. The output represents L. The eight types of triangular MFs viz. Z1, Z2, Z3, Z4, Z5, Z6, Z7 and Z8 are designed for each input as illustrated in Fig. 13 and eight types of triangular MFs viz. FL1, FL2, FL3, FL4, FL5, FL6, FL7 and FL8 are designed for each output as illustrated in Fig. 14.

TABLE I InPut and Output Fuzzy Sets for Expert Systems

\begin{tabular}{lllll}
\hline \hline Schemes & System Variable & Linguistic Variable & MF Names & MF Type \\
\multirow{2}{*}{ MFES-1 } & Inputs (1) & Phase Angle & Small, Normal and Large & Triangular \\
& Output (1) & Zone & Reverse Zone, No-Fault and Forward Zone & Triangular \\
\hline \multirow{2}{*}{ MFES-2 } & Inputs (7) & FCIa, FCIb, FCIc, FCId, FCIe, FCIf and ZSCC & Low and High & Trapezoidal \\
& Output (7) & A, B,C, D, E,F,G & Faulty and Healthy & Triangular \\
\hline \multirow{2}{*}{ MFES-3 } & Inputs (6) & FCZa, FCZb, FCZc, FCZd, FCZe, FCZf, & Z1, Z2, Z3, Z4, Z5, Z6, Z7 and Z8 & Triangular \\
& Output (1) & L & FL1, FL2, FL3, FL4, FL5, FL6, FL7 and FL8 & Triangular \\
\hline \hline
\end{tabular}




\section{Fuzzy Inference Engine}

After making input output fuzzy sets, fuzzy rules are constructed to evaluate faulty zone detection, fault type classification and fault location. The OR operator is performed with min operation and AND operator is performed with max operation. The fuzzy rules are framed in the form of IF-THEN based on the conditions and conclusions. The combining result of each rule is evaluated by fuzzy set operations. This mechanism is known as inference engine.

\section{Defuzzification}

The aggregation is changed into a numerical value for outputs. It is performed by the defuzzification technique. A single number indicates the fuzzy sets outcome. Centroid technique is employed to change the finalized fuzzy conclusions into numerical values. Fig. 15 shows centroid defuzzification for MFES-1 during reverse fault in MATLAB fuzzy software. Fig. 16 shows centroid defuzzification for MFES-2 during 'Ag' fault in MATLAB fuzzy software. Fig. 17 shows centroid defuzzification for MFES-3 during fault at $65 \mathrm{~km}$ in MATLAB fuzzy software.

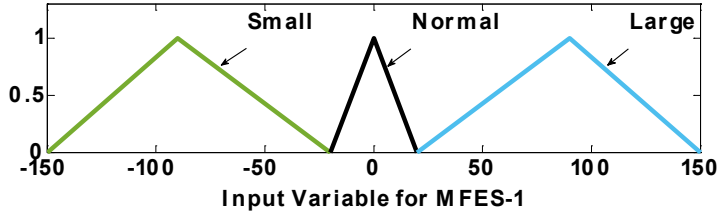

Fig. 9. Degree of MF for input variable of MFES-1.

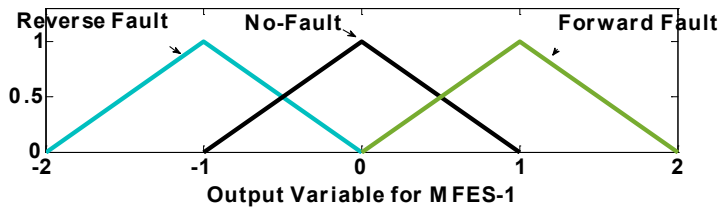

Fig. 10. Degree of MF for output variable of MFES-1.

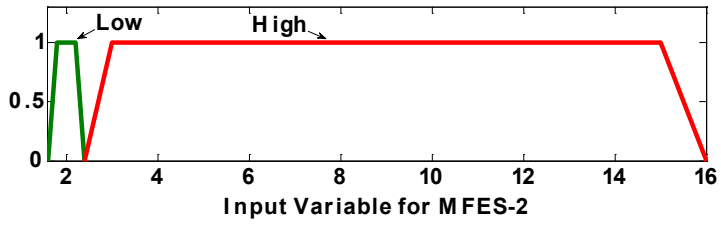

Fig. 11. Degree of MF for each input variable of MFES-2

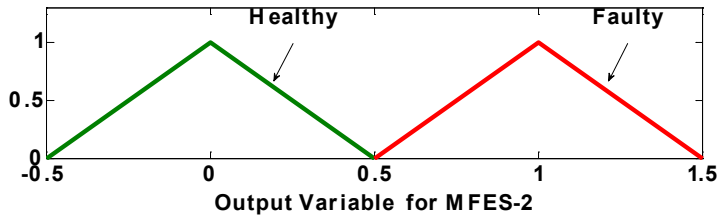

Fig. 12. Degree of MF for each output variable of MFES-2.

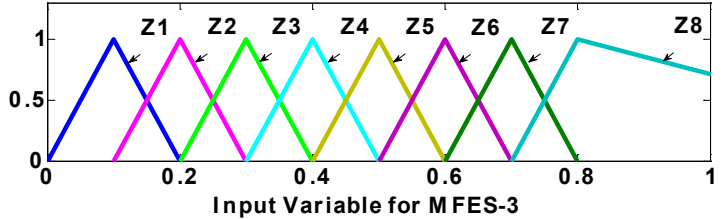

Fig. 13. Degree of MF for each input variable of MFES-3.

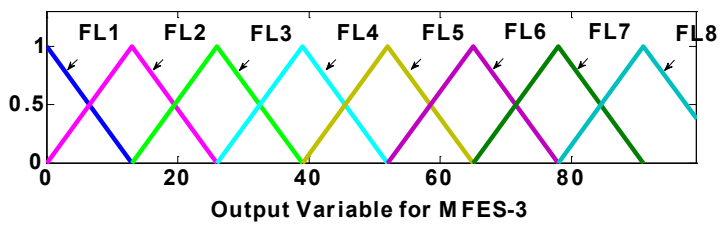

Fig. 14. Degree of MF for output variable of MFES-3.

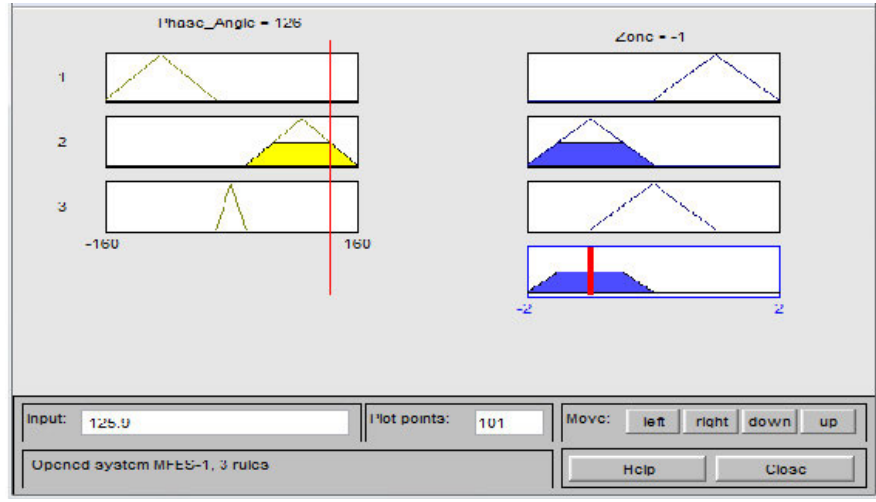

Fig. 15. Defuzzification for MFES-1.

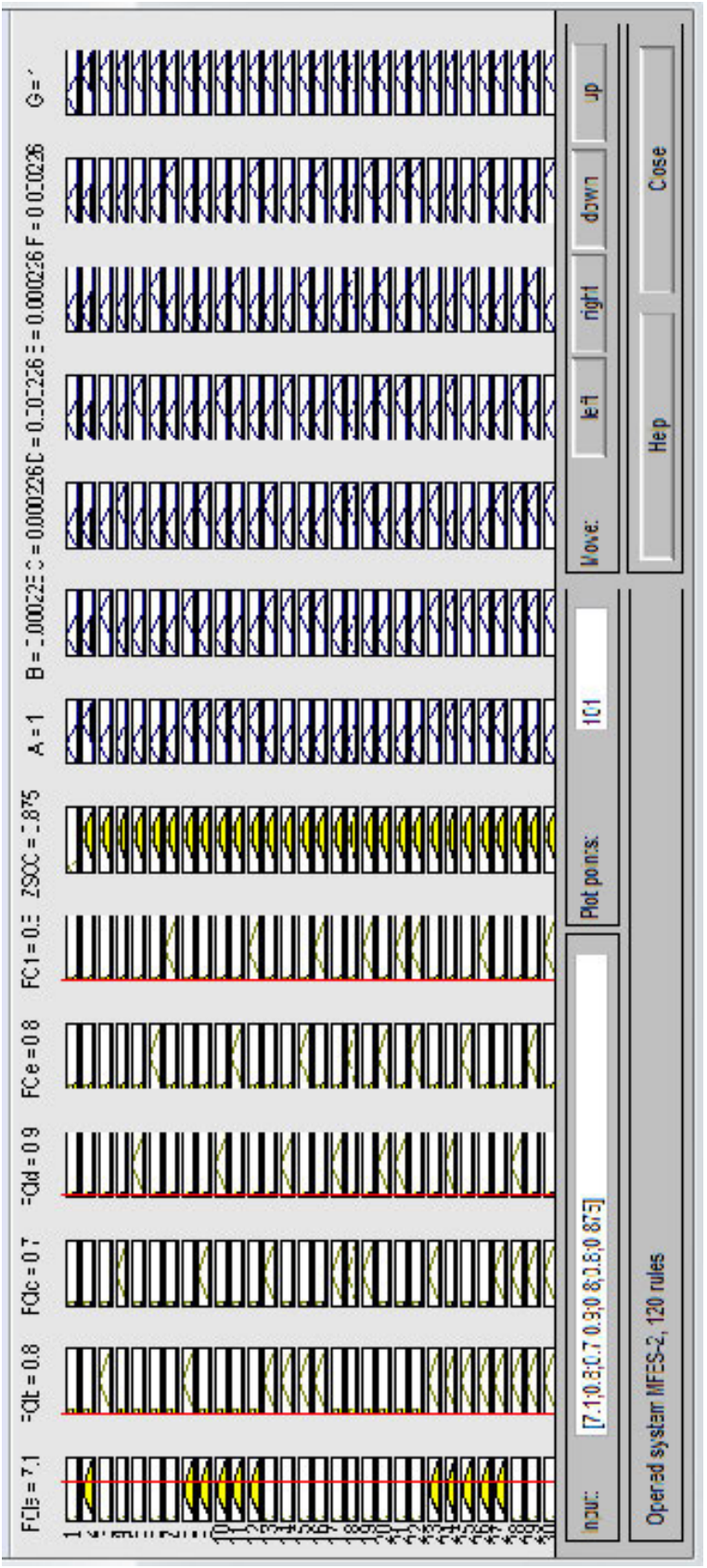

Fig. 16. Defuzzification for MFES-2. 


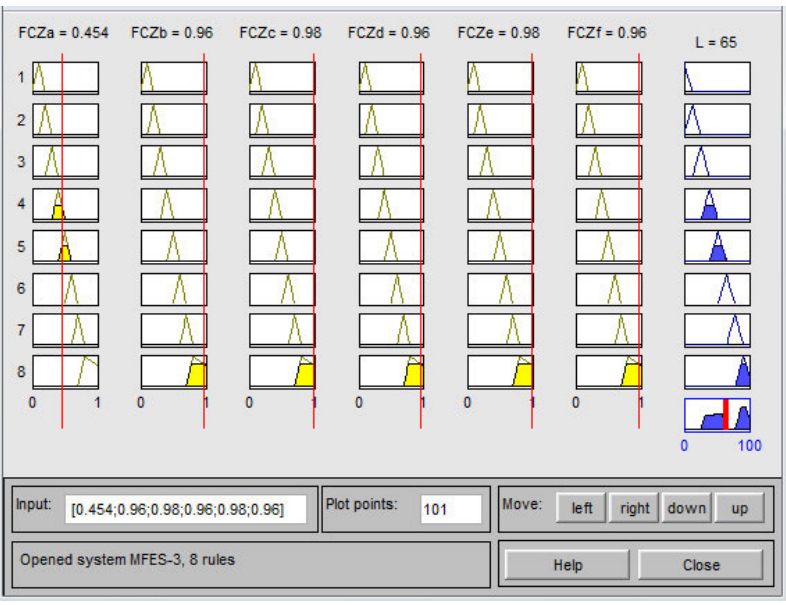

Fig. 17. Defuzzification for MFES-3.

\section{RESUlts AND Discussions}

Proposed fuzzy based fault direction relaying, classification and location schemes are tested for different fault cases. The change of parameters considering fault types (forward and revere faults), fault inception angles, fault locations (including near end and far end) and fault resistances. The total number of test fault cases employed for testing the proposed fuzzy based scheme is 10,000 cases. The performance of MFES based schemes and comparison study is discussed in the following subsections.

\section{A. The Performance of Directional Relaying, Fault Classifier and Fault Locator}

Prior to classification, directional relaying and location estimation has been carried out. The fault direction relaying scheme traces the presence of faults and also determines the direction of faults. When there is no fault the response will be zero. If any fault occurs, the response starts changing to either -1 or +1 based on the reverse or forward faults, respectively. The simulation results of direction relaying detector and locator for various types of fault with changing fault location in reverse or forward direction from bus- 2 are given in Table II. The simulation results of direction relaying detector and locator for various types of fault with changing fault resistance in reverse or forward direction from bus-2 are given in Table III. The simulation results of direction relaying detector and locator for various types of fault with changing fault inception angle in reverse or forward direction from bus-2 are given in Table IV. It is confirmed that most of the test samples have identified zone and located the faults.

The response of the proposed scheme is also tested for faults occurring in the boundary locations, i.e., near end and far end/remote faults. The traditional distance relaying technique reach setting is up to $85-95 \%$ of total length of line. Thus it is difficult to find the faults that occur between $95 \%$ and $100 \%$ of the length. Considering the objective of enhancing the reach setting value, the proposed scheme is developed. The response of the scheme for different far end/remote faults has been investigated by changing the fault location between $97 \mathrm{~km}$ and $99 \mathrm{~km}$ in each zone in steps of $1 \mathrm{~km}$. The near-end faults occurring very close to bus-2 location in both the zones (within $3 \%$ of the line) and the voltages at the relay will be very small. Therefore, the near end faults are challenging for the traditional impedance relay. The response of the scheme for different near end faults has been investigated by changing the fault location between $1 \mathrm{~km}$ and $3 \mathrm{~km}$ in each zone in steps of $1 \mathrm{~km}$. The simulation results of different fault types at boundary locations are outlined in Table V. Thus the proposed scheme can protect total transmission line length and reach value of the line is $99.7 \%$. The maximum absolute error percentage was $0.54 \%$ under phase-to-phase and phase-to-ground faults (including reverse, forward, near end and remote end faults. The $\%$ error in estimated fault location is calculated using (3).

$$
\% \text { Error }=\frac{L-L o}{\text { Line Length }}
$$

The simulation results of MFES-2 corresponding to various fault scenarios with change in fault parameters such as fault type, fault location, fault resistance and fault inception angle are listed in Table VI. The proposed MFES-2 scheme classified the faults correctly. It can be confirmed that the response time is within one cycle of post fault for all the tested fault scenarios.

Table II. Performance of Direction Relaying and Location Schemes in Case Of Different Fault Locations

\begin{tabular}{|c|c|c|c|c|c|}
\hline $\begin{array}{l}\text { Fault } \\
\text { Zone }\end{array}$ & Type & $\mathbf{L}$ & MFES-1 & $\begin{array}{l}\text { MFES-3 } \\
\text { (Lo)(km) }\end{array}$ & $\begin{array}{c}\% \\
\text { Error }\end{array}$ \\
\hline \multirow[t]{11}{*}{ Reverse } & $\mathrm{Ag}$ & 5 & -1 & 5.211 & 0.106 \\
\hline & $\mathrm{ABg}$ & 9 & -1 & 8.902 & -0.049 \\
\hline & $\mathrm{ABCg}$ & 18 & -1 & 18.425 & 0.213 \\
\hline & ABCDg & 26 & -1 & 26.172 & 0.086 \\
\hline & $\mathrm{ABCDEg}$ & 32 & -1 & 31.833 & -0.084 \\
\hline & $\mathrm{ABCDEFg}$ & 41 & -1 & 41.236 & 0.118 \\
\hline & $\mathrm{AB}$ & 56 & -1 & 56.183 & 0.092 \\
\hline & $\mathrm{ABC}$ & 67 & -1 & 67.266 & 0.133 \\
\hline & $\mathrm{ABCD}$ & 74 & -1 & 74.246 & 0.123 \\
\hline & ABCDE & 83 & -1 & 83.124 & 0.062 \\
\hline & ABCDEF & 95 & -1 & 94.842 & -0.079 \\
\hline \multirow[t]{11}{*}{ Forward } & $\mathrm{Ag}$ & 6 & 1 & 6.263 & 0.132 \\
\hline & $\mathrm{ABg}$ & 15 & 1 & 14.936 & -0.032 \\
\hline & $\mathrm{ABCg}$ & 24 & 1 & 24.480 & 0.240 \\
\hline & $\mathrm{ABCDg}$ & 38 & 1 & 37.812 & -0.094 \\
\hline & $\mathrm{ABCDEg}$ & 45 & 1 & 44.655 & -0.173 \\
\hline & $\mathrm{ABCDEFg}$ & 59 & 1 & 59.234 & 0.117 \\
\hline & $\mathrm{AB}$ & 63 & 1 & 62.580 & -0.210 \\
\hline & $\mathrm{ABC}$ & 72 & 1 & 72.004 & 0.002 \\
\hline & $\mathrm{ABCD}$ & 81 & 1 & 80.691 & -0.155 \\
\hline & $\mathrm{ABCDE}$ & 89 & 1 & 89.374 & 0.187 \\
\hline & ABCDEF & 94 & 1 & 94.526 & 0.263 \\
\hline
\end{tabular}


TABle III. Performance of Direction Relaying and Location Schemes in Case of Different Fault Resistances at 33 Km Location

\begin{tabular}{rlcccc}
\hline $\begin{array}{c}\text { Fault } \\
\text { Zone }\end{array}$ & \multicolumn{1}{c}{ Type } & $\begin{array}{c}\mathbf{R} \\
(\boldsymbol{\Omega})\end{array}$ & MFES-1 & $\begin{array}{c}\text { MFES-3 } \\
(\mathbf{L o})(\mathbf{k m})\end{array}$ & $\begin{array}{c}\text { \% } \\
\text { Error }\end{array}$ \\
\hline Reverse & Ag & 110 & -1 & 33.373 & 0.187 \\
& ABg & 90 & -1 & 33.514 & 0.257 \\
& ABCg & 70 & -1 & 33.439 & 0.220 \\
& ABCDg & 50 & -1 & 33.262 & 0.131 \\
& ABCDEg & 30 & -1 & 32.836 & -0.082 \\
& ABCDEFg & 10 & -1 & 33.328 & 0.164 \\
& AB & 56 & -1 & 33.863 & 0.432 \\
& ABC & 67 & -1 & 33.699 & 0.350 \\
& ABCD & 74 & -1 & 33.218 & 0.109 \\
& ABCDE & 83 & -1 & 32.941 & -0.030 \\
& ABCDEF & 95 & -1 & 33.360 & 0.180 \\
Forward & 110 & 1 & 33.252 & 0.126 \\
& ABg & 90 & 1 & 32.960 & -0.020 \\
& ABCg & 70 & 1 & 32.981 & -0.010 \\
& ABCDg & 50 & 1 & 32.693 & -0.154 \\
& ABCDEg & 30 & 1 & 34.002 & 0.501 \\
& ABCDEFg & 10 & 1 & 32.340 & -0.330 \\
AB & 63 & 1 & 33.458 & 0.229 \\
ABC & 72 & 1 & 33.024 & 0.012 \\
& ABCD & 81 & 1 & 33.698 & 0.349 \\
ABCDE & 89 & 1 & 32.756 & -0.122 \\
& ABCDEF & 94 & 1 & 33.215 & 0.108 \\
\hline
\end{tabular}

TABLE IV. Performance of Direction Relaying and Location Schemes in Case Of Different Fault Inception Angles at 55 Km Location

\begin{tabular}{clcccc}
\hline $\begin{array}{c}\text { Fault } \\
\text { Zone }\end{array}$ & \multicolumn{1}{c}{ Type } & $\begin{array}{c}\boldsymbol{\phi} \\
(\mathbf{o})\end{array}$ & MFES-1 & $\begin{array}{c}\text { MFES-3 } \\
(\mathbf{L o})(\mathbf{k m})\end{array}$ & $\begin{array}{c}\text { \% } \\
\text { Error }\end{array}$ \\
\hline Reverse & Ag & 30 & -1 & 54.698 & -0.151 \\
& ABg & 60 & -1 & 55.374 & 0.187 \\
& ABCg & 90 & -1 & 54.624 & -0.188 \\
& ABCDg & 120 & -1 & 55.252 & 0.126 \\
& ABCDEg & 150 & -1 & 55.490 & 0.245 \\
& ABCDEFg & 180 & -1 & 55.604 & 0.302 \\
& AB & 210 & -1 & 55.188 & 0.094 \\
& ABC & 240 & -1 & 54.785 & -0.108 \\
& ABCD & 270 & -1 & 55.331 & 0.166 \\
& ABCDE & 300 & -1 & 55.384 & 0.192 \\
& ABCDEF & 330 & -1 & 54.792 & -0.104 \\
& Ag & 30 & 1 & 55.048 & 0.024 \\
& ABg & 60 & 1 & 55.434 & 0.217 \\
& ABCg & 90 & 1 & 55.266 & 0.133 \\
& ABCDg & 120 & 1 & 54.869 & -0.066 \\
& ABCDEg & 150 & 1 & 56.008 & 0.504 \\
& ABCDEFg & 180 & 1 & 55.432 & 0.216 \\
& AB & 210 & 1 & 54.924 & -0.038 \\
ABC & 240 & 1 & 55.182 & 0.091 \\
& ABCD & 270 & 1 & 55.160 & 0.080 \\
& ABCDE & 300 & 1 & 54.988 & -0.006 \\
& ABCDEF & 330 & 1 & 55.564 & 0.282 \\
\hline
\end{tabular}

TABle V. Performance of Direction Relaying and Location Schemes in Case of Different Near End Remote End Faults

\begin{tabular}{|c|c|c|c|c|c|}
\hline $\begin{array}{l}\text { Fault } \\
\text { Zone }\end{array}$ & Type & $\mathbf{L}$ & MFES-1 & $\begin{array}{l}\text { MFES-3 } \\
\text { (Lo)(km) }\end{array}$ & $\begin{array}{c}\% \\
\text { Error }\end{array}$ \\
\hline \multirow{11}{*}{$\begin{array}{l}\text { Near } \\
\text { End } \\
\text { Faults }\end{array}$} & $\mathrm{Ag}$ & $1 \mathrm{~km}$ in zone- 1 & -1 & 1.334 & 0.167 \\
\hline & $\mathrm{ABg}$ & $1 \mathrm{~km}$ in zone- 2 & 1 & 1.253 & 0.127 \\
\hline & $\mathrm{ABCg}$ & $1 \mathrm{~km}$ in zone-1 & -1 & 0.680 & -0.160 \\
\hline & $\mathrm{ABCDg}$ & $2 \mathrm{~km}$ in zone- 1 & -1 & 2.096 & 0.048 \\
\hline & $\mathrm{ABCDEg}$ & $1 \mathrm{~km}$ in zone- 1 & -1 & 1.532 & 0.266 \\
\hline & $\mathrm{ABCDEFg}$ & $3 \mathrm{~km}$ in zone- 2 & 1 & 3.432 & 0.216 \\
\hline & $\mathrm{AB}$ & $1 \mathrm{~km}$ in zone- 1 & -1 & 1.286 & 0.143 \\
\hline & $\mathrm{ABC}$ & $3 \mathrm{~km}$ in zone- 2 & 1 & 2.645 & -0.178 \\
\hline & $\mathrm{ABCD}$ & $2 \mathrm{~km}$ in zone- 1 & -1 & 2.021 & 0.011 \\
\hline & $\mathrm{ABCDE}$ & $1 \mathrm{~km}$ in zone- 2 & 1 & 1.540 & 0.270 \\
\hline & ABCDEF & $2 \mathrm{~km}$ in zone- 1 & -1 & 2.460 & 0.230 \\
\hline \multirow{11}{*}{$\begin{array}{l}\text { Far End } \\
\text { Faults }\end{array}$} & $\mathrm{Ag}$ & $99 \mathrm{~km}$ in zone-2 & 1 & 99.122 & 0.061 \\
\hline & $\mathrm{ABg}$ & $98 \mathrm{~km}$ in zone- 2 & 1 & 97.890 & -0.055 \\
\hline & $\mathrm{ABCg}$ & $97 \mathrm{~km}$ in zone- 2 & 1 & 97.462 & 0.231 \\
\hline & $\mathrm{ABCDg}$ & $99 \mathrm{~km}$ in zone- 1 & -1 & 99.260 & 0.130 \\
\hline & $\mathrm{ABCDEg}$ & $98 \mathrm{~km}$ in zone- 2 & 1 & 97.910 & -0.045 \\
\hline & ABCDEFg & $97 \mathrm{~km}$ in zone-2 & 1 & 97.454 & 0.227 \\
\hline & $\mathrm{AB}$ & $99 \mathrm{~km}$ in zone- 2 & 1 & 99.180 & 0.090 \\
\hline & $\mathrm{ABC}$ & $98 \mathrm{~km}$ in zone- 1 & -1 & 98.500 & 0.250 \\
\hline & $\mathrm{ABCD}$ & $97 \mathrm{~km}$ in zone- 2 & 1 & 97.422 & 0.211 \\
\hline & $\mathrm{ABCDE}$ & $99 \mathrm{~km}$ in zone- 1 & -1 & 98.646 & -0.177 \\
\hline & $\mathrm{ABCDEF}$ & $98 \mathrm{~km}$ in zone- 2 & 1 & 98.380 & 0.190 \\
\hline
\end{tabular}

Fig. 18 explains the output of MFES-1 in which 'Zone' goes -1 at $40 \mathrm{~ms}$ showing there is reverse fault. Fig. 19 explains the outputs of MFES-2 in which 'A and G' phases go 1 at $45 \mathrm{~ms}$, with other outputs B, $\mathrm{C} \mathrm{D} \mathrm{E}$ and F remaining 0 (no fault) showing there is Ag-fault. Fig. 20 explains the output of MFES-3 in which 'L' goes 65 at $40 \mathrm{~ms}$ showing there is a fault occurring at $65 \mathrm{~km}$. Following directional relaying, classification and fault location estimation, the comparison with other techniques are discussed in the next subsection.

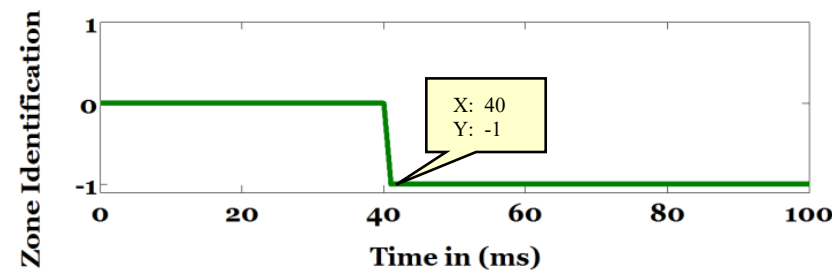

Fig. 18. Output of MFES-1 during reverse fault at $40 \mathrm{~ms}$. 


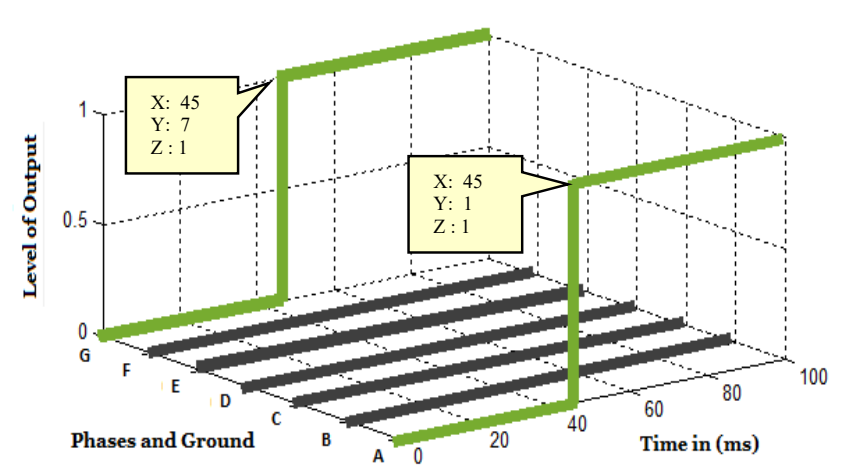

Fig. 19. Output of MFES-2 during Ag fault at $40 \mathrm{~ms}$.

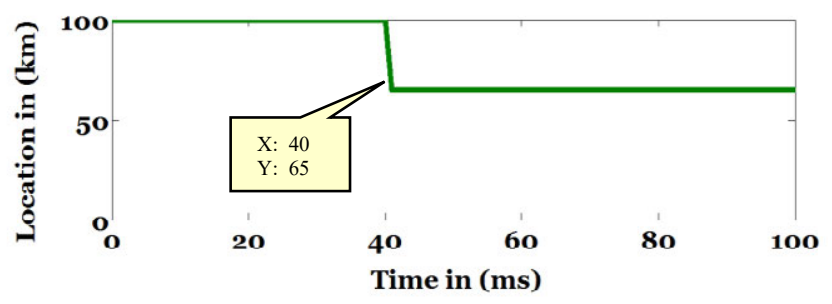

Fig. 20. Output of MFES-3 during fault at $40 \mathrm{~ms}$ at $65 \mathrm{~km}$.

\section{B. Comparison with Other Techniques}

To further judge the expediency of the scheme, the comparison analysis has been carried out for reach setting and scheme used. The proposed scheme has been compared with the other ones reported in papers listed in Table VII. Most of the existing schemes in six phase line [4]-[8] are non-directional relays. The proposed relay is directional and deciphered the difficulty of distinguishing between reverse and forward faults and providing the precise fault location in six-phase lines. ANN based fault location [7], directional relying [15] and classification [5] techniques are developed. However, the drawback of ANN techniques is that it requires large data samples set to learn the relationship between fault patterns with changing fault parameters and no-fault which needs tedious training process. Also, the choice of the training algorithms, mean square error goal, number of epochs, hidden layers, activation functions and number of neurons is a difficult task. Thus, a technique without complex computation and without training will be more advantageous, like the proposed fuzzy technique. The reach setting of line length in [11] is $99.5 \%$. The test results of the proposed method in the present paper; the reach setting is $99.7 \%$ without training effort. A fuzzy technique [24] is addressed for 3-phase line and is also directional relay, but its reach is up to $99 \%$ and it does not deal with a six phase line. The proposed scheme not only gives the minimum error but also attains the same with better reach setting in six phase line. Simulations confirmed high efficacy and satisfactory performance of the proposed directional relaying, classification and fault location scheme compared with other reported approaches. Thus, the fuzzy relay is a better option for direction relaying, classification and fault location compared to all other techniques in six phase line.

\section{CONCLUSION}

This study dealt with performance improvement of zone identification and fault location in six phase line. The fault protection is achieved through the MFES scheme, which works on phase angle, currents and impedance samples acquired at single terminal of line. The results show that the proposed MFES based scheme can be effectively applied for zone identification of six phase line. Simulation results show that the proposed relays could give protection to both the sections table Vi. Performance of Fault Classifier in Case Of Different Fault Locations, Resistances and InCEPTION ANGLes

\begin{tabular}{|c|c|c|c|c|c|c|c|c|c|c|c|c|}
\hline \multirow{2}{*}{$\begin{array}{l}\text { Parameter } \\
\text { Varied }\end{array}$} & \multirow{2}{*}{$\begin{array}{l}\text { Fault } \\
\text { Type }\end{array}$} & \multirow{2}{*}{$\begin{array}{c}\mathrm{L} \\
(\mathbf{k m})\end{array}$} & \multirow{2}{*}{$\begin{array}{c}\mathrm{R} \\
(\Omega)\end{array}$} & \multirow{2}{*}{\multicolumn{2}{|c|}{$\begin{array}{l}\Phi \text { Time } \\
\text { (o) (ms) }\end{array}$}} & \multicolumn{7}{|c|}{ MFES-2 } \\
\hline & & & & & & $\mathbf{A}$ & B & $\mathrm{C}$ & D & $\mathbf{E}$ & $\mathbf{F}$ & G \\
\hline \multirow[t]{11}{*}{$\mathrm{L}$} & $\mathrm{Ag}$ & 4 & 50 & 45 & 2 & 1 & 0 & 0 & 0 & 0 & 0 & 1 \\
\hline & $\mathrm{ABg}$ & 15 & 50 & 45 & 6 & 1 & 1 & 0 & 0 & 0 & 0 & 1 \\
\hline & $\mathrm{ABCg}$ & 23 & 50 & 45 & 5 & 1 & 1 & 1 & 0 & 0 & 0 & 1 \\
\hline & ABCDg & 29 & 50 & 45 & 2 & 1 & 1 & 1 & 1 & 0 & 0 & 1 \\
\hline & $\mathrm{ABCDEg}$ & 38 & 50 & 45 & 7 & 1 & 1 & 1 & 1 & 1 & 0 & 1 \\
\hline & ABCDEFg & 46 & 50 & 45 & 7 & 1 & 1 & 1 & 1 & 1 & 1 & 1 \\
\hline & $\mathrm{ABg}$ & 53 & 0 & 45 & 3 & 1 & 1 & 0 & 0 & 0 & 0 & 0 \\
\hline & $\mathrm{ABCg}$ & 61 & 0 & 45 & 2 & 1 & 1 & 1 & 0 & 0 & 0 & 0 \\
\hline & $\mathrm{ABCDg}$ & 79 & 0 & 45 & 4 & 1 & 1 & 1 & 1 & 0 & 0 & 0 \\
\hline & $\mathrm{ABCDEg}$ & 88 & 0 & 45 & 3 & 1 & 1 & 1 & 1 & 1 & 0 & 0 \\
\hline & $\mathrm{ABCDEFg}$ & 94 & 0 & 45 & 2 & 1 & 1 & 1 & 1 & 1 & 1 & 0 \\
\hline \multirow[t]{6}{*}{$\mathrm{R}$} & $\mathrm{Ag}$ & 41 & 110 & 80 & 7 & 1 & 0 & 0 & 0 & 0 & 0 & 1 \\
\hline & $\mathrm{ABg}$ & 41 & 90 & 80 & 2 & 1 & 1 & 0 & 0 & 0 & 0 & 1 \\
\hline & $\mathrm{ABCg}$ & 41 & 70 & 80 & 1 & 1 & 1 & 1 & 0 & 0 & 0 & 1 \\
\hline & $\mathrm{ABCDg}$ & 41 & 50 & 80 & 4 & 1 & 1 & 1 & 1 & 0 & 0 & 1 \\
\hline & $\mathrm{ABCDEg}$ & 41 & 30 & 80 & 3 & 1 & 1 & 1 & 1 & 1 & 0 & 1 \\
\hline & $\mathrm{ABCDEFg}$ & 41 & 10 & 80 & 3 & 1 & 1 & 1 & 1 & 1 & 1 & 1 \\
\hline \multirow[t]{11}{*}{$\phi$} & $\mathrm{Ag}$ & 12 & 100 & 30 & 5 & 1 & 0 & 0 & 0 & 0 & 0 & 1 \\
\hline & $\mathrm{ABg}$ & 12 & 100 & 60 & 1 & 1 & 1 & 0 & 0 & 0 & 0 & 1 \\
\hline & $\mathrm{ABCg}$ & 12 & 100 & 90 & 3 & 1 & 1 & 1 & 0 & 0 & 0 & 1 \\
\hline & $\mathrm{ABCDg}$ & 12 & 100 & 120 & 2 & 1 & 1 & 1 & 1 & 0 & 0 & 1 \\
\hline & ABCDEg & 12 & 100 & 150 & 2 & 1 & 1 & 1 & 1 & 1 & 0 & 1 \\
\hline & $\mathrm{ABCDEFg}$ & 12 & 100 & 180 & 5 & 1 & 1 & 1 & 1 & 1 & 1 & 1 \\
\hline & $\mathrm{ABg}$ & 12 & 0 & 210 & 7 & 1 & 1 & 0 & 0 & 0 & 0 & 0 \\
\hline & $\mathrm{ABCg}$ & 12 & 0 & 240 & 4 & 1 & 1 & 1 & 0 & 0 & 0 & 0 \\
\hline & $\mathrm{ABCDg}$ & 12 & 0 & 270 & 2 & 1 & 1 & 1 & 1 & 0 & 0 & 0 \\
\hline & $\mathrm{ABCDEg}$ & 12 & 0 & 300 & 2 & 1 & 1 & 1 & 1 & 1 & 0 & 0 \\
\hline & $\mathrm{ABCDEFg}$ & 12 & 0 & 330 & 1 & 1 & 1 & 1 & 1 & 1 & 1 & 0 \\
\hline
\end{tabular}

TABLE VII. COMPARISON WITH OTHER EXISTING WorKS

\begin{tabular}{|c|c|c|c|c|c|}
\hline $\begin{array}{l}\text { Ref. } \\
\text { No. }\end{array}$ & $\begin{array}{c}\text { Proposed } \\
\text { Scheme }\end{array}$ & $\begin{array}{l}\text { Protection } \\
\text { Type }\end{array}$ & $\begin{array}{l}\text { Reach } \\
\text { Setting }\end{array}$ & $\begin{array}{c}\% \\
\text { Error }\end{array}$ & $\begin{array}{c}\text { Transmission } \\
\text { Line }\end{array}$ \\
\hline [4] & ANN & Classification & - & - & 6-Phase \\
\hline [5] & ANN & Classification & - & - & 6-Phase \\
\hline [6] & ANN & $\begin{array}{l}\text { Classification } \\
\text { and Location }\end{array}$ & - & 0.41 & 6-Phase \\
\hline [7] & ANN & Location & - & 0.73 & 6-Phase \\
\hline [8] & ANN & $\begin{array}{l}\text { Classification } \\
\text { and Location }\end{array}$ & - & 0.688 & 6-Phase \\
\hline [11] & $\begin{array}{l}\text { Modular } \\
\text { Neuro- } \\
\text { Wavelet }\end{array}$ & $\begin{array}{c}\text { Zone } \\
\text { Identification } \\
\text { and fault } \\
\text { Location }\end{array}$ & 99.5 & 0.675 & 6-Phase \\
\hline [15] & ANN & $\begin{array}{l}\text { Directional } \\
\text { relaying }\end{array}$ & 99.5 & - & 3-Phase \\
\hline [24] & $\begin{array}{c}\text { Fuzzy } \\
\text { Inference } \\
\text { System }\end{array}$ & $\begin{array}{c}\text { Directional } \\
\text { Relaying, } \\
\text { Classification } \\
\text { and Location }\end{array}$ & 95 & 2 & 3-Phase \\
\hline $\begin{array}{l}\text { Proposed } \\
\text { method }\end{array}$ & $\begin{array}{l}\text { Fuzzy } \\
\text { Inference } \\
\text { System }\end{array}$ & $\begin{array}{c}\text { Directional } \\
\text { relaying, } \\
\text { Classification } \\
\text { and Location }\end{array}$ & 99.7 & 0.504 & 6-Phase \\
\hline
\end{tabular}


of the six phase line. Neither fault inception angle information nor fault type is a prerequisite for this scheme. The schemes have the advantage of automatically tuning the MFs for an optimal design. The proposed directional relaying offers protection up to $99.7 \%$ of the line in both reverse zone and primary zone. Even though the proposed scheme is simple and easy, the improvement is significant.

\section{REFERENCES}

[1] James, R. Stewart, Thomas F. Dorazio and Matthew T. Brown, "Insulation Coordination, Environmental and System Analysis of Existing Double Circuit Line Reconfigured to Six-Phase Operation," IEEE Transactions on Power Delivery, vol.7, no.3, pp. 1628-1633, 1992.

[2] S.S. Venkata, W.C. Guyter, J.Kondragunta and N.B. Butt, "EPPC - A Computer Program for Six-Phase Transmission Line Design," IEEE Transactions on Power Apparatus and Systems, vol. PAS-101, no. 7, pp. 1859-1869, 1982.

[3] Laurie Oppel Edw ard Krizauskas, "Evaluation of the Performance of Line Protection Schemes on the NYSEG Six Phase Transmission System," IEEE Transactions on Power Delivery, vol.14, no.1, pp. 110-115, 1990.

[4] Ebha Koley, Anamika Jain, A.S.Thoke, Abhinav Jain and Subhojit Ghosh, "Detection and Classification of Faults on Six Phase Transmission Line using ANN," IEEE International Conference on Computer \& Communication Technology, MNNIT, Allahabad, pp. 100-103, 2011.

[5] Ravi Kumar, Ebha Koley, Anamika Yadav and A.S. Thoke, "Fault Classification of Phase to Phase Fault in Six Phase Transmission Line using Haar Wavelet and ANN," in Proceedings of IEEE International Conference on Signal Processing and Integrated Network., Noida, India, pp. 5-8, 2014.

[6] A. Naresh Kumar and Chakravarthy M, "Simultaneous Fault Classification and Localization Scheme in Six Phase Transmission Line Using Artificial Neural Networks," Journal of Advanced Research in Dynamical \& Control Systems, vol.10, no.3, pp. 342-349, 2018.

[7] Ebha Koley, Anamika Yadav and Aniruddha Santosh Thoke, "A New Single-Ended Artificial Neural Network-based Protection Scheme for Shunt Faults in Six-Phase Transmission Line," International Transactions on Electrical Energy Systems, vol.25, no.7, pp. 1257-1280, 2015.

[8] Ebha Koley, Khushaboo Verma and Subhojit Ghosh, "An Improved Fault Detection Classification and Fault Location Scheme based on Wavelet Transform and Artificial Neural Networks for Six Phase Transmission Line using Single End Data Only," Springer Plus, 2015.

[9] Apostolov AP and George W, "Protecting NYSEG's Six-Phase Transmission Line," IEEE computer applications in power, vol.5, no.4, pp. 33-36, 1992.

[10] Apostolov AP and Raffensperger RG (1996), "Relay Protection Operation for Faults on NYSEG's Six Phase Transmission Line," IEEE Trans Power Delivery, vol.11, no.1, pp. 191-196.

[11] Ebha Koley, Khushaboo Verma and Subhojit Ghosh, "A Modular NeuroWavelet Based Non-Unit Protection Scheme for Zone Identification and Fault Location in Six Phase Transmission Line," Neural Computing and Applications, vol.28, no.6, pp. 1369-1385, 2017.

[12] Anamika Yadav and Aleena Swetapadma, "A Novel Transmission Line Relaying Scheme for Fault Detection And Classification using Wavelet Transform and Linear Discriminant Analysis," Ain Shams Engineering Journal, vol.6, pp. 199-209, 2015.

[13] Aleena Swetapadma and Anamika Yadav, "High-Speed Directional Relaying using Adaptive Neuro-Fuzzy Inference System and Fundamental Component of Currents," IEEJ Transactions on Electrical and Electronic Engineering, vol.10, pp. 653-663, 2015.

[14] S.R. Samantaray, "Decision Tree-based Fault Zone Identification and Fault Classification in Flexible AC Transmissions-based Transmission Line," IET Generation, Transmission \& Distribution, vol.3, no.5, pp. 425436, 2009.

[15] Anamika Yadav, Yajnaseni Dash and V. Ashok, "ANN based directional Relaying Scheme for Protection of Korba-Bhilai Transmission Line of Chhattisgarh State," Protection and Control of Modern Power Systems, no.1, 2016.

[16] García, C. G., E. R. Nunez-Valdez, V. García-Díaz, C. Pelayo G-Bustelo and J. M. Cueva-Lovelle, "A Review of Artificial Intelligence in the Internet of Things," International Journal of Interactive Multimedia and
Artificial Intelligence, vol.5, no.4, pp. 9-20, 2019.

[17] Benamina, M., B. Atmani, and S. Benbelkacem, "Diabetes Diagnosis by Case-Based Reasoning and Fuzzy Logic," International Journal of Interactive Multimedia and Artificial Intelligence, vol.5, no.3, pp. 72-80, 2018.

[18] Farhane, N., I. Boumhidi, and J. Boumhidi, "Smart Algorithms to Control a Variable Speed Wind Turbine," International Journal of Interactive Multimedia and Artificial Intelligence, vol.4, no.6, pp. 88-95, 2017.

[19] Praveen Kumar Mishra and Anamika Yadav, "A Single Ended Fuzzy Based Directional Relaying Scheme For Transmission Line Compensated by Fixed Series Capacitor," ISDA, VIT Vellore, pp. 6-8, 2018.

[20] Aleena Swetapadma and Anamika Yadav, "Fuzzy Inference System Approach for Locating Series, Shunt, and Simultaneous Series-Shunt Faults in Double Circuit Transmission Lines," Computational Intelligence and Neuroscience, vol. 2015, Article ID 620360, 12 pages, 2015. https:// doi.org/10.1155/2015/620360.

[21] A. Naresh Kumar and Chakravarthy. M, "Fuzzy Inference System Based Distance Estimation Approach for Multi Location and Transforming Phase to Ground Faults in Six Phase Transmission Line," International Journal of Computational Intelligence Systems, vol.11, no.1, pp. 757-769, 2018.

[22] A. Naresh Kumar, Ch Sanjay and M Chakravarthy "Fuzzy Expert System based Protection for Double Circuit Incomplete Journey Transmission Lines," International Journal of Computational Intelligence \& IoT, vol.2, no.1, pp. 351-355, 2019.

[23] A. Naresh Kumar, Ch Sanjay and M Chakravarthy, "Fuzzy Inference System-based Solution to Locate the Cross-Country Faults in Parallel Transmission Line," International Journal of Electrical Engineering \& Education, 2019.

[24] Anamika Yadav and Aleena Swetapadma, "Enhancing the performance of transmission line directional relaying, fault classification and fault location schemes using fuzzy inference systems," IET Generation, Transmission and Distribution, vol.9, no.6, pp. 580-591, 2015.

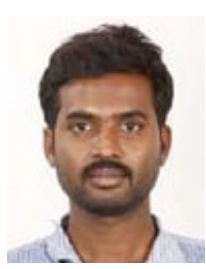

\section{A. Naresh Kumar}

A Naresh Kumar received the B. Tech. degree in Electrical and Electronics Engineering from Jawaharlal Nehru Technological University, Jagitiala, India in 2011. He received his M.Tech degree in Electrical Engineering from National Institute of Technology, Raipur, India, in 2013. Presently he is pursuing his Ph.D. from department of Electrical and Electronics Engineering, GITAM University, Hyderabad. His areas of interest are power system protection, smart grid and soft computing applications.

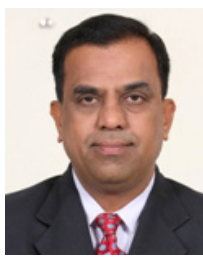

\section{Ch. Sanjay}

Prof. Ch. Sanjay (UG/PG/Ph.D from reputed Government Universities in India) had joined GITAM University, Hyderabad as a Distinguished Professor and Founder Director, from June, 2009 till 2014, currently working as Principal and Dean, School of Technology, and has been a member of Board of Management, IQAC and Academic Council since 2009. He was Keynote Speaker for 64 International/ National Conference and Co-Chair for 8 International Conferences held abroad. He is Member, Editorial Board/ Reviewer for more than 20 international journals and evaluated 19 Doctorial theses in Mechanical / Manufacturing / Management / Information Technology and presently guiding 10 Research Scholars. To his credit, Prof. Sanjay has 4 books published by reputed publishers and authored more than 60 Research papers in Peer Reviewed, Indexed Journals and Conference Proceedings and completed 6 international research projects. Recipient of many International and National Awards such as Academic Excellence, Research Excellence, Best Engineer, Best Principal, Best Academic Administrator, Education Leadership and Engineers Educator award.

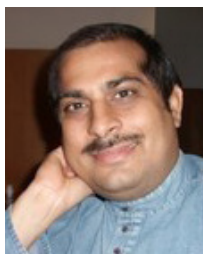

\section{Chakravarthy}

Dr. M Chakravarthy received his Phd degree in Electrical and Electronics Engineering from Jawaharlal Nehru Technological University, Hyderabad, India in 2013. He is Professor in the department of Electrical and Electronics Engineering, Vasavi College of Engineering, Hyderabad, India. His research areas are smart grid, DC-DC converters, automation and industrial control. He is a member of IEEE. 